\title{
Anticoagulant therapy in elderly patients with atrial fibrillation : A time series study using the nationwide claim database in Japan
}

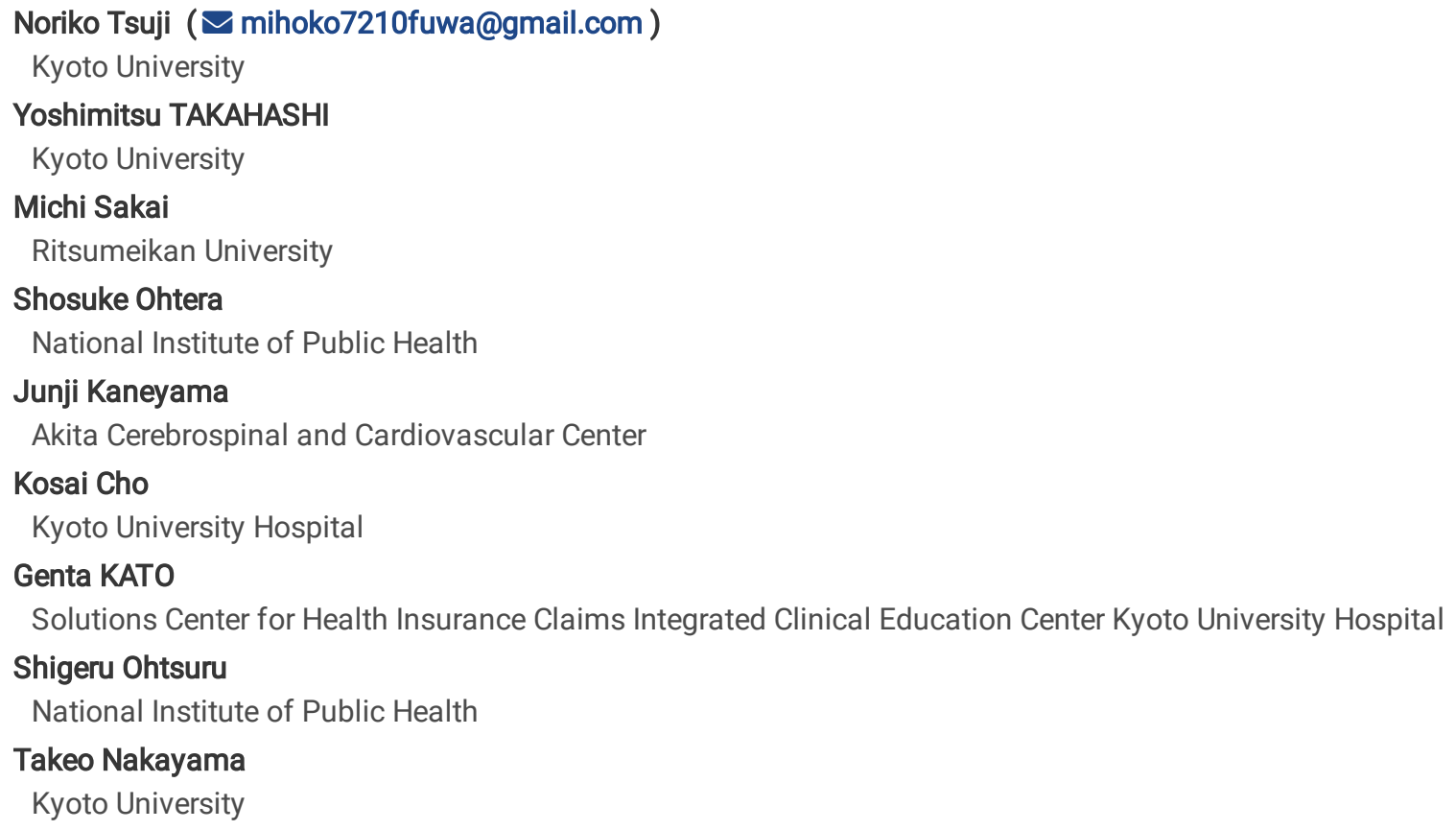




\section{Abstract}

Background and aim: The introduction of direct oral anticoagulants (DOACs) has greatly changed the use of anticoagulant therapy in patients with non-valvular atrial fibrillation (Af). However, few studies have reported on the current state of anticoagulant therapy at the national level. This study aimed to examine changes in the proportions of oral anticoagulant (OAC) prescriptions (4 DOACs and a vitamin $\mathrm{K}$ antagonist: VKA) in patients with non-valvular Af aged $\geq 65$ years, taking into consideration the risk of cerebral infarction and bleeding.

Methods: Anticoagulant prescriptions in outpatients with Af were temporally analyzed using the nationwide claims database in Japan. The proportion of anticoagulants prescribed to Af patients aged $\geq 65$ years was determined. Trends in anticoagulant prescriptions were examined according to cerebral infarction and bleeding risk.

Results: The proportion of anticoagulant prescriptions for 12,076 Af patients aged $\geq 65$ years in Japan increased from $41 \%$ in 2011 to $56 \%$ in 2015. The proportion of prescriptions for DOACs surpassed that of VKA. An increase in DOAC prescriptions was accompanied by an increase in the proportion of anticoagulant prescriptions in each group according to the CHA2DS2-VASc and HAS-BLED scores. The proportion of anticoagulant prescriptions for patients with a high risk of developing cerebral infarction and bleeding showed a marked increase.

Conclusion: Trends in anticoagulant prescriptions in patients with non-valvular AfAf in Japan showed a marked increase in DOAC prescriptions. The widespread use of DOACs greatly changes the profiles of cerebral infarction and bleeding risks, which are related to the prescription of anticoagulant therapy in patients with non-valvular Af.

\section{Background}

Atrial fibrillation (Af) is a common arrhythmia in the elderly. Af is associated with the development of cardiogenic cerebral infarction ${ }^{1}$, with serious outcomes including physical dysfunction and death².

In order to prevent the development of cardiogenic cerebral infarction, Af patients are conventionally prescribed warfarin potassium (vitamin $\mathrm{K}$ antagonist: VKA), an anticoagulant agent. With the release of dabigatran in 2011, prescriptions for direct oral anticoagulants (DOACs) have increased rapidly ${ }^{3-9}$. While recent guidelines around the world recommend prescribing DOACs ${ }^{10-13}$, it remains unclear how indications and risk of bleeding, a serious side effect of anticoagulants, are considered when these drugs are prescribed. In fact, there have been no reports on the current state of anticoagulant prescriptions at the national level. Accordingly, the present study aimed to reveal the state of anticoagulant prescriptions in Japanese elderly Af patients aged $\geq 65$ years, as well as the risk of cerebral infarction and bleeding. To this end, trends in anticoagulant prescriptions were examined using data obtained from the National Database of Health Insurance Claims and Specific Health Checkups of Japan (NDB), a database that covers more than $95 \%$ of all claims data across Japan.

\section{Methods}

1) Study design and database used

This time-series study used a sampling dataset of $\mathrm{NDB}^{14}$. Of the entire dataset available at the time of the study (including data from inpatients, outpatients, and pharmacy claims, as well as DPC data; note that pharmacy claims include data for November, which are linked to outpatient data), we applied to and obtained approval from the Ministry of Health, Labour and Welfare for the use of patients claims data from October of each year from 2011 to 2015. In this dataset we used outpatients and pharmacy claims data. This NDB sampling dataset comprises data ( $10 \%$ each for inpatients and DPC data, and $1 \%$ each for outpatients and pharmacy claims data) extracted from a highly exhaustive claims database that stores claims information collected from over $95 \%$ of the Japanese population, from infants to elderly individuals ${ }^{14-18}$. This database includes data on patient age and sex, ambulatory services and diagnoses, medical treatment, and aid, as well as drug dispensation. All diagnoses in the database were coded according to the 10th revision of the International Classification of Diseases (ICD-10). Pharmacy claims include various information on outpatient prescriptions dispensed from Japan pharmacies, such as dispensing/prescription dates and the number of tablets dispensed. Prescription handouts were coded according to the Anatomical Therapeutic Chemical Classification System.

\section{2) Subjects}

The following selection criteria were used: patients aged $\geq 65$ years with a disease code corresponding to the ICD-10 code (I48: atrial fibrillation) in their medical claims ${ }^{19}$. The exclusion criteria were patients with a disease code for valvular Af or valvular disease recorded in their medical claims (i.e., those with an ICD-10 code 105, 106, 134, or I35), those with venous thromboembolism (I802 or I269), and those who 
underwent artificial joint replacement (total hip arthroplasty, knee arthroplasty). The extracted non-valvular Af patients were considered the subjects of this study (hereafter, Af patients). Oral anticoagulants (OACs) were defined as VKA and four DOACs (dabigatran, rivaroxaban, apixaban, and edoxaban), coded in pharmacy claims data as 3332-D01280, 3339-D07082, D07086, D03213, and D09546, according to the ATC classification.

Patients who had been prescribed an antiplatelet agent (AP) were extracted, and those who had been prescribed both anticoagulants and AP were considered candidates for anticoagulant therapy. For drug codes, medical claim codes corresponding to the ATC classification numbers were used ${ }^{19}$. The list of drug and disease codes used for subject extraction is shown in Supplementary Table S1.

3) Evaluation indices

The primary evaluation indices were proportions of Af patients who were prescribed VKA, DOACs, and AP in October of each year from 2011 to 2015 , as well as those who were not prescribed any of the above-mentioned drugs, among all Af patients.

4) Measurement item

Subject characteristics included age, sex, comorbidities (cerebral infarction, myocardial infarction, ischemic heart disease, peripheral artery disease, heart failure, chronic kidney disease, liver disease, hemorrhagic disease, alcoholic disease, hypertension, and diabetes mellitus), and concomitant drugs (non-steroidal anti-inflammatory drugs [NSAIDs] ). Each disease was extracted using disease codes recorded in medical claims ${ }^{19}$ corresponding to ICD-10 codes. Patients with hypertension (defined as those who were prescribed antihypertensive drugs) and patients with diabetes (defined as those who were prescribed anti-diabetic drugs) were extracted and included as subjects. Patients with renal dysfunction, defined as those with a treatment code corresponding to dialysis recorded in their medical claims ${ }^{19}$, were also included. The list of drug and disease codes used for subject extraction is shown in Supplementary Table S1.

\section{5) $\mathrm{CHA}_{2} \mathrm{DS}_{2}$-VASc and HAS-BLED scores}

The $\mathrm{CHA}_{2} \mathrm{DS}_{2}$-VASc score was used to assess the risk of developing cerebral infarction, and a total score was obtained by adding 1 point each for the presence of heart failure, hypertension, diabetes mellitus, and vascular disease (history of myocardial infarction, peripheral arterial disease, aortic plaques), female sex, and age 65-74 years, and 2 points each for age $\geq 75$ years and prior cerebral infarction/TIA 20. The HAS-BLED score was used to assess the risk of bleeding during anticoagulant therapy, and a total score was obtained by adding 1 point each for hypertension, prior history of cerebral infarction/TIA, kidney dysfunction (dialysis, kidney transplant), liver dysfunction (cirrhosis), prior bleeding or predisposition to bleeding, age $\geq 65$ years, use of AP and NSAIDs, alcoholism, and unstable INR ${ }^{21}$. Since INR values were not available, the highest HAS-BLED score was 8 points.

6) Analyses

Data were analyzed using descriptive statistics, followed by the Cochrane Armitage test to examine changes over time in prescriptions for each drug. The entire Af patient population was divided into four groups: two groups according to the $\mathrm{CHA}_{2} \mathrm{DS} \mathrm{S}_{2}-\mathrm{VASc}_{\mathrm{Score}}(<2$ or $\geq 2)$ and two groups according to the HAS-BLED score $(<3, \geq 3)$, based on data from to 2011-2015. The numbers of VKA and DOAC prescriptions and proportions of prescriptions for each of these drugs among all Af patients were calculated for each group. The first of the four groups comprised patients with "low thrombus risk and low bleeding risk," for whom anticoagulant therapy is only considered an option (Group 1); the second group comprised patients with "low risk of developing cerebral infarction and high risk of bleeding," for whom caution is required when prescribing anticoagulant therapy (Group 2); the third group comprised patients with "high risk of developing cerebral infarction and low risk of bleeding," for whom anticoagulant therapy is recommended (Group 3); and the fourth group comprised patients with "both high risk of developing cerebral infarction and high risk of bleeding," for whom clinical judgment is difficult due to opposing risks and benefits of anticoagulant therapy for non-valvular Af patients (Group 4).

Statistical analyses were performed using R (version 3.3.2) (Copyright (C) 2016 The R Foundation for Statistical Computing), with a twotailed test at a significance level of $5 \%$.

\section{Results}

1)Subject extraction

The same subject extraction process was followed over a 5-year period. The representative results from 2015 are described below. 
A total of 14,363 Af patients aged $\geq 65$ years were extracted from the 2015 outpatient claims data. Of these, 12,076 Af patients were subjected to analysis after excluding 2,049 patients with valvular Af or valvular disease, 173 patients with venous thromboembolism, and 65 patients who were prescribed two or more anticoagulants. The characteristics of the patients are summarized in Table 1. Mean age (SD) was 78.8 (7.7) years, mean $\mathrm{CHADS}_{2}$ score (SD) was 2.5 (1.4), mean $\mathrm{CHA}_{2} \mathrm{DS}_{2}$-VASc score (SD) was 4.1 (1.5), and mean HAS-BLED score (SD) was 2.6 (1.1). Subjects were divided into those who were prescribed anticoagulants $(n=6,761)$ and those who were not $(n=5,315)$; the former group was further classified into those who were prescribed VKA $(n=2,991)$ and those who were prescribed DOACs $(n=3,770)($ Figure 1). The results from the datasets (2011 to 2014) were obtained using the same procedure.

2) Time trends in the numbers of oral anticoagulant prescriptions

Time trends in the number of patients who were prescribed VKA, each of the four DOACs, and that of all DOAC-prescribed patients combined, among all Af patients aged $\geq 65$ years, are shown in Fig. 2. As the total number of Af patients increased from 2011 to 2015 , the number of patients who were prescribed DOACs significantly increased (339 to 3770), whereas the number of patients who were prescribed VKA significantly decreased (3051 to 2991).

3) Proportions of prescriptions for anticoagulants and AP among all Af patients

Time trends in the proportions of prescriptions for anticoagulants and AP among all Af patients aged $\geq 65$ years are shown in Fig. 3. The proportion of anticoagulant prescriptions increased from 41-56\% between 2011 and 2015. The proportion of Af patients who were not prescribed anticoagulants decreased from 56-43\% between 2011 and 2015 . The proportion of AP prescriptions decreased year by year; in $2015,1 \%$ were prescribed AP alone, and $0.8 \%$ were prescribed AP and anticoagulants concomitantly.

4) Changes over time in the proportions of prescriptions stratified by cerebral infarction risk and bleeding risk

Changes over time in the proportions of anticoagulant prescriptions for Af patients from 2011 to 2015 are shown by group in Table 2 . The proportion of anticoagulant prescriptions overall changed from 18-26\% in Group 1, 37-24\% in Group 2, 33-49\% in Group 3, and 54-66\% in Group 4, with the proportion of DOAC prescriptions reaching $20 \%, 16 \%, 29 \%$, and $35 \%$ in Groups 1 , 2, 3, and 4, respectively, in 2015 . In 2015 , there were 11,642 Af patients in Groups 3 and 4 combined, and these patients accounted for $96 \%$ of all Af patients that year. In these 11,642 Af patients, the proportion of those who were prescribed anticoagulants was $58 \%$ and that of those who were prescribed DOACs was $32 \%$. The proportion of OAC prescriptions was higher in Group 4 than in Group 3.

\section{Discussion}

With an increase in DOAC prescriptions, the proportion of anticoagulant prescriptions for Af patients aged $\geq 65$ years increased from $41-$ $56 \%$ from 2011 to 2015 . The proportion of anticoagulant prescriptions increased from $33-49 \%$ in the group of patients with a $\mathrm{CHA}_{2} \mathrm{DS}_{2}-$ VASc score $\geq 2$ and HAS-BLED scores $<3$ (i.e., for whom anticoagulant therapy is recommended), and from $54-66 \%$ in the group of patients with a $\mathrm{CHA}_{2} \mathrm{DS}_{2}$-VASc score $\geq 2$ and HAS-BLED scores $\geq 3$, from 2011 to 2015 . These findings from highly exhaustive NDB data shed light on how anticoagulants are prescribed in Japan.

1) Changes over time in the numbers of anticoagulant prescriptions

The number of anticoagulant prescriptions overall increased from 2011 to 2015; the number of DOAC prescriptions surpassed that of VKA prescriptions, which showed a decreasing trend. These results were consistent with previous reports from Denmark, Germany, France, and the United States ${ }^{3-7}$, as well as in Japanese registry studies ${ }^{8-9}$. Clinical studies that examined four DOACs demonstrated no differences between VKA and DOACs ${ }^{22-27}$ and clinical practice guidelines in Japan, and those of other countries now recommend the use of DOACs. This may explain our results as well as those reported previously. Meanwhile, Behdarvand et al. pointed out that intense sales promotion efforts by pharmaceutical companies that market DOACs toward Australian clinicians might have been a driving force behind the increase in DOAC prescriptions ${ }^{28}$. Although there are no such reports in Japan, since DOACs are more expensive than VKA, we cannot deny the possibility that aggressive information provision by companies may have influenced clinicians' prescribing behaviors.

2) Proportion of anticoagulant prescriptions among all Af patients

As for the cause of the increase in the proportion of anticoagulant prescriptions among all Af patients ( $41 \%$ in 2011 to $56 \%$ in 2015 ), it is possible that the introduction of DOACs may have helped reduce the number of patients for whom the attending physician avoided prescribing an anticoagulant. It is conceivable that, when VKA was prescribed as a single therapy, a considerable number of patients were not prescribed anticoagulants. In addition, from 2011 to 2015, there was an increase in the number of Af patients. This suggests that more

Page $4 / 13$ 
patients were likely to have been diagnosed with Af, and thus, the number of new patients with Af who were prescribed DOACs also increased. However, the proportion of anticoagulant prescriptions was lower than that reported previously in studies from other countries ${ }^{3-7}$. Given that the risk of developing cerebral infarction is lower among Japanese non-valvular Af patients than among European and American patients ${ }^{29}$, the lower proportion of anticoagulant prescriptions in Japan might reflect a cautious attitude on the part of physicians who prescribe anticoagulant therapy. Moreover, physicians may hold up prescriptions for elderly patients due to a high number of comorbidities and concomitant drugs. Although the efficacy of AP has not been demonstrated ${ }^{30}$, it is still prescribed to some patients with coronary artery disease who have undergone $\mathrm{PCl}$ or $\mathrm{CABG}^{31}$. However, as concomitant anticoagulants have been reported to be associated with poor prognosis $^{32}$, the use of AP is expected to decrease further in the future.

3) Changes over time in the proportion of prescriptions stratified by cerebral infarction risk and bleeding risk

The proportion of anticoagulant prescriptions, especially DOACs, increased in all four groups. However, this may reflect possible overuse of anticoagulants in Group 1 and 2 patients, who have a low need to receive anticoagulant therapy. Moreover, the proportion of anticoagulant prescriptions was higher in Group 4 patients who had a high risk of bleeding compared to Group 3 patients, and for whom anticoagulant therapy was recommended. This likely resulted from a prescribing behavior that only considers the risk of cerebral infarction when prescribing OAC; that is, patients with a high HAS-BLED score were administered OAC. Compared with prescription trends in other countries ${ }^{4}$, our results suggest the possibility that anticoagulants may be prescribed based only on cerebral infarction risk. It is also possible that the attitudes of clinicians may change in the direction of "if in doubt, prescribe." With the introduction of anticoagulant therapy, there has emerged a need to consider safety and reduce risks. Efforts should be made to control blood pressure to prevent bleeding, to instruct patients to reduce alcohol consumption, and to avoid the use of NSAIDs and other drugs ${ }^{33}$. Whether the increase in DOAC administration reduced the risk of developing cerebral infarction or increased the risk of bleeding in Af patients should be evaluated in future studies.

\section{Study Limitations}

This study has several limitations. First, the NDB sampling dataset comprised single-month data and not a continuous set of data. Accordingly, whether patients were newly prescribed DOACs or switched from VKA to DOACs could not be verified. Similarly, at the time of OAC prescription, whether it was prescribed in consideration of $\mathrm{CHA}_{2} \mathrm{DS}_{2}$-VASc and HAS-BLED scores could not be verified. Second, since insurance claims data contain no descriptions of laboratory test values (INR, kidney function, blood pressure, body weight, etc.), $\mathrm{CHA}_{2} \mathrm{DS}_{2}{ }^{-}$ VASc and HAS-BLED scores were calculated based on disease names and drugs used. This likely resulted in higher scores relative to actual risks, given that patients with hypertension were identified based on the presence of administered anti-hypertensive drugs, that is, some patients who were included in this patient group might not have had hypertension. For example, there might have been cases in which patients were assigned a disease code for hypertension so that antihypertensive drugs could be administered for the purpose of treating lgA nephropathy. Even though such cases might not be common, this could have led to high $\mathrm{CHA}_{2} \mathrm{DS}_{2}$-VASc and HAS-BLED scores. Finally, comorbidities and concomitant drugs were also likely confounders, but were not fully assessed in this analysis.

\section{Conclusions}

From 2011 to 2015, anticoagulant prescriptions for patients with non-valvular Af rapidly shifted from VKA to DOACs, and the proportion of total anticoagulant prescriptions increased in Japan. While the proportion of anticoagulant prescriptions for patients with a high risk of cerebral infarction increased, that for patients at a high risk of bleeding also increased. Due to the widespread use of DOACs, the profiles of these two risks, which are associated with anticoagulant prescriptions in non-valvular Af patients, are drastically changing.

\section{Declarations}

\section{Ethical considerations}

This study complied with the guidelines of the Ministry of Health, Labour and Welfare regarding the provision of health insurance claims information and special health check-up information (revised April 2015) ${ }^{16}$ and was approved by the Ethics Committee of Kyoto University Faculty of Medicine (approval number: R1013).

\section{Consent for publication}

Not applicable" in this section.

\section{Availability of data and materials}


The datasets used and/or analyzed during the current study are available from the corresponding author on reasonable request.

\section{Conflict of interests}

The authors have no conflicts of interest regarding the contents of this study.

\section{Funding}

The budget of Department of Health Informatics, Graduate School of Medicine and Public Health, Kyoto University, Japan.

\section{Authors' contributions}

NT, MS, SO, YT, GK and TN designed the study. KC, SO, and GK obtained NDB sampling data, and NT analyzed the dataset. NT wrote the manuscript, JK, MS, SO, YT and TN revised the manuscript. All authors read and approved the final manuscript.

\section{Acknowledgements}

The authors thank Dr. T. Iwao and Dr. Y. Nakatani for their assistance with data acquisition and management.

\section{Authors' information}

${ }^{a}$ Department of Health Informatics, Graduate School of Medicine and Public Health, Kyoto University, Kyoto, Japan; ${ }^{b}$ Comprehensive Unit for Health Economic Evidence Review and Decision Support, Ritsumeikan University, Kyoto, Japan; ${ }^{\mathrm{C}}$ Center for Outcomes Research and Economic Evaluation for Health, National Institute of Public Health, Wako, Japan; ${ }^{d}$ Akita Cerebrospinal and Cardiovascular Center, Second Department of Cardiology, Akita, Japan; e Department of Primary Care and Emergency Medicine, Kyoto University Hospital, Kyoto Japan; ${ }^{f}$ Solutions Center for Health Insurance Claims Integrated Clinical Education Center Kyoto University Hospital, Kyoto, Japan.

\section{Abbreviations}

Af

Atrial fibrillation

VKA

vitamin $\mathrm{K}$ antagonist

DOACs

direct oral anticoagulants

NDB

the National Database of Health Insurance Claims and Specific Health Checkups of Japan

ICD-10

the 10th revision of the International Classification of Diseases

ATC

the Anatomical Therapeutic Chemical Classification System.

OACs

oral anticoagulants

AP

antiplatelet agent

NSAIDs

non-steroidal anti-inflammatory drugs

$\mathrm{CHA}_{2} \mathrm{DS}_{2}$-VASc score

heart failure, hypertension, age $\geq 75 y e a r s(d o u b l e d)$,diabetes mellitus, prior cerebral infarction or TIA(doubled), vascular disease, age 65-74 years, female sex

HAS-BLED score

hypertension, renal and hepatic dysfunction, stroke, bleeding, age $\geq 65$ years, concomitant antiplatelet drugs and NSAIDs, alcoholism TIA

transient ischemic attack

$\mathrm{PCl}$

percutaneous coronary intervention 
CABG

coronary artery bypass grafting

\section{References}

1. Wolf PA, Abbott RD, Kannel WB. Atrial fibrillation as an independent risk factor for stroke: The framingham study. Stroke. 1991;22(8):983988. doi:10.1161/01.STR.22.8.983.

2. Lin HJ, Wolf PA, Kelly-Hayes M, Beiser AS, Kase CS, Benjamin EJ, and D'Agostino RB. Stroke severity in atrial fibrillation: The Framingham study. Stroke. 1996;27:1760-1764. doi:10.1161/01.STR.27.10.1760.

3. Hohnloser $\mathrm{SH}$, Basic E, Nabauer M. Uptake in antithrombotic treatment and its association with stroke incidence in atrial fibrillation: insights from a large German claims database. Clin Res Cardiol. 2019 Sep;108(9):1042-1052. doi: 10.1007/s00392-019-01437-7. Epub 2019 Feb 15. PMID: 30771066.

4. Camm AJ, Accetta G, Ambrosio G, Atar D, Bassand JP, Berge E, Cools F, Fitzmaurice DA, Goldhaber SZ, Goto S, Haas S, Kayani G, Koretsune Y, Mantovani LG, Misselwitz F, Oh S, Turpie AG, Verheugt FW, Kakkar AK; GARFIELD-AF Investigators. Evolving antithrombotic treatment patterns for patients with newly diagnosed atrial fibrillation. Heart. 2017 Feb 15;103(4):307-314. doi: 10.1136/heartjnl-2016309832. Epub 2016 Sep 19. PMID: 27647168; PMCID: PMC5293840.

5. Alalwan AA, Voils SA, Hartzema AG. Trends in utilization of warfarin and direct oral anticoagulants in older adult patients with atrial fibrillation. Am J Health Syst Pharm. 2017 Aug 15;74(16):1237-1244. doi: 10.2146/ajhp160756. Epub 2017 Jun 26. PMID: 28652320.

6. Maura G, Billionnet C, Drouin J, Weill A, Neumann A, Pariente A. Oral anticoagulation therapy use in patients with atrial fibrillation after the introduction of non-vitamin K antagonist oral anticoagulants: findings from the French healthcare databases, 2011-2016. BMJ Open. 2019 Apr 20;9(4):e026645. doi: 10.1136/bmjopen-2018-026645. PMID: 31005934; PMCID: PMC6500377.

7. Olesen JB, Sørensen R, Hansen ML, Lamberts M, Weeke P, Mikkelsen AP, Køber L, Gislason GH, Torp-Pedersen C, Fosbøl EL. Non-vitamin $\mathrm{K}$ antagonist oral anticoagulation agents in anticoagulant naïve atrial fibrillation patients: Danish nationwide descriptive data 2011-2013. Europace. 2015 Feb;17(2):187-93. doi: 10.1093/europace/euu225. Epub 2014 Sep 18. PMID: 25236181.

8. Yamashita Y, Uozumi R, Hamatani Y, Esato M, Chun YH, Tsuji H, Wada H, Hasegawa K, Ogawa H, Abe M, Morita S, Akao M. Current Status and Outcomes of Direct Oral Anticoagulant Use in Real-World Atrial Fibrillation Patients - Fushimi AF Registry. Circ J. 2017 Aug 25;81(9):1278-1285. doi: 10.1253/circj.CJ-16-1337. Epub 2017 Apr 19. PMID: 28428449.

9. Inoue H, Atarashi H, Kodani E, Okumura K, Yamashita T, Origasa H, Sakurai M, Kawamura Y, Kubota I, Matsumoto K, Kaneko Y, Ogawa S, Aizawa Y, Chinushi M, Kodama I, Watanabe E, Koretsune Y, Okuyama Y, Shimizu A, Igawa O, Bando S, Fukatani M, Saikawa T, Chishaki A; JRHYTHM Registry Investigators. Regional Differences in Frequency of Warfarin Therapy and Thromboembolism in Japanese Patients With Non-Valvular Atrial Fibrillation - Analysis of the J-RHYTHM Registry. Circ J. 2016 Jun 24;80(7):1548-55. doi: 10.1253/circj.CJ-16-0300. Epub 2016 Jun 1. PMID: 27251064.

10. Kirchhof P, Benussi S, Kotecha D, Ahlsson A, Atar D, Casadei B, Castella M, Diener HC, Heidbuchel H, Hendriks J, Hindricks G, Manolis AS, Oldgren J, Popescu BA, Schotten U, Van Putte B, Vardas P; ESC Scientific Document Group. 2016 ESC Guidelines for the management of atrial fibrillation developed in collaboration with EACTS. Eur Heart J. 2016 Oct 7;37(38):2893-2962. doi: 10.1093/eurheartj/ehw210. Epub 2016 Aug 27. PMID: 27567408.

11. January CT, Wann LS, Calkins H, Chen LY, Cigarroa JE, Cleveland JC Jr, Ellinor PT, Ezekowitz MD, Field ME, Furie KL, Heidenreich PA, Murray KT, Shea JB, Tracy CM, Yancy CW. 2019 AHA/ACC/HRS Focused Update of the 2014 AHA/ACC/HRS Guideline for the Management of Patients With Atrial Fibrillation: A Report of the American College of Cardiology/American Heart Association Task Force on Clinical Practice Guidelines and the Heart Rhythm Society in Collaboration With the Society of Thoracic Surgeons. Circulation. 2019 Jul 9;140(2):e125-e151. doi: 10.1161/CIR.0000000000000665. Epub 2019 Jan 28. Erratum in: Circulation. 2019 Aug 6;140(6):e285. PMID: 30686041.

12. Macle L, Cairns JA, Andrade JG, Mitchell LB, Nattel S, Verma A; CCS Atrial Fibrillation Guidelines Committee. The 2014 Atrial Fibrillation Guidelines Companion: A Practical Approach to the Use of the Canadian Cardiovascular Society Guidelines. Can J Cardiol. 2015 Oct;31(10):1207-18. doi: 10.1016/j.cjca.2015.06.005. PMID: 26429352. 
13. JCS Joint Working Group. Guidelines for elective percutaneous coronary intervention in patients with stable coronary artery disease (JCS 2011) published in 2012: Digest version. Circ J. 2013;77(6):1590-1607. doi:10.1253/circj.CJ-66-0065.

14. Ministry of Health, Labour, and welfare. Website regarding national database of health insurance claims and specific health checkups of Japan Home Page. https://www.mhlw.go.jp/stf/seisakunitsuite/bunya/kenkou_iryou/iryouhoken/reseputo/index.html. [cited 2021 Jun 30].

15. Ministry of Health, Labour and welfare. Situation regarding digitization of health insurance claims 2015.

https://www.mhlw.go.jp/file/06-Seisakujouhou-12400000-Hokenkyoku/0000099002.pdf . [cited 2021 Jun 30].

16. Guidelines for the Provision of National Database of Health Insurance Claims and Specific Health Checkups of Japan (NDB)(2015, April revised). http://www.mhlw.go.jp/file/05-Shingikai-12401000-Hokenkyoku-Soumuka/0000064238_3.pdf. [cited 2021 Jun 30].

17. Shinichiro K, Tatsuya N, Tomoya M, Yuichi N, Tsuneyuki H, Hiroki M, Genta K, Tomoaki I.. National Database of Health Insurance Claims and Specific Health Checkups of Japan (NDB): Outline and Patient-Matching Technique. bioRxiv. 2018:280008. doi:10.1101/280008.

18. Okamoto E. Linkage rate between data from health checks and health insurance claims in the Japan national database. $J$ Epidemiol. 2014;24(1):77-83. doi:10.2188/jea.JE20130075.

19. Various Information of Medical Fee in Japan. http://www.iryohoken.go.jp/shinryohoshu/. [cited 2021 Jun 30$].$

20. Lip GY, Nieuwlaat R, Pisters R, Lane DA, Crijns HJ. Refining clinical risk stratification for predicting stroke and thromboembolism in atrial fibrillation using a novel risk factor-based approach: the euro heart survey on atrial fibrillation. Chest. 2010 Feb;137(2):263-72. doi: 10.1378/chest.09-1584. Epub 2009 Sep 17. PMID: 19762550.

21. Pisters R, Lane DA, Nieuwlaat R, de Vos CB, Crijns HJ, Lip GY. A novel user-friendly score (HAS-BLED) to assess 1-year risk of major bleeding in patients with atrial fibrillation: the Euro Heart Survey. Chest. 2010 Nov;138(5):1093-100. doi: 10.1378/chest.10-0134. Epub 2010 Mar 18. PMID: 20299623.

22. Connolly SJ, Ezekowitz MD, Yusuf S, Eikelboom J, Oldgren J, Parekh A, Pogue J, Reilly PA, Themeles E, Varrone J, Wang S, Alings M, Xavier D, Zhu J, Diaz R, Lewis BS, Darius H, Diener HC, Joyner CD, Wallentin L; RE-LY Steering Committee and Investigators. Dabigatran versus warfarin in patients with atrial fibrillation. N Engl J Med. 2009 Sep 17;361(12):1139-51. doi: 10.1056/NEJMoa0905561. Epub 2009 Aug 30. Erratum in: N Engl J Med. 2010 Nov 4;363(19):1877. PMID: 19717844.

23. ROCKET AF Study Investigators. Rivaroxaban-once daily, oral, direct factor Xa inhibition compared with vitamin $\mathrm{K}$ antagonism for prevention of stroke and Embolism Trial in Atrial Fibrillation: rationale and design of the ROCKET AF study. Am Heart J. 2010 Mar;159(3):340-347.doi: 10.1016/j.ahj.2009.11.025.

24. Avezum A, Lopes RD, Schulte PJ, Lanas F, Gersh BJ, Hanna M, Pais P, Erol C, Diaz R, Bahit MC, Bartunek J, De Caterina R, Goto S, Ruzyllo W, Zhu J, Granger CB, Alexander JH. Apixaban in Comparison With Warfarin in Patients With Atrial Fibrillation and Valvular Heart Disease: Findings From the Apixaban for Reduction in Stroke and Other Thromboembolic Events in Atrial Fibrillation (ARISTOTLE) Trial. Circulation. 2015 Aug 25;132(8):624-32. doi: 10.1161/CIRCULATIONAHA.114.014807. Epub 2015 Jun 23. PMID: 26106009.

25. Giugliano RP, Ruff CT, Braunwald E, Murphy SA, Wiviott SD, Halperin JL, Waldo AL, Ezekowitz MD, Weitz JI, Špinar J, Ruzyllo W, Ruda M, Koretsune Y, Betcher J, Shi M, Grip LT, Patel SP, Patel I, Hanyok JJ, Mercuri M, Antman EM; ENGAGE AF-TIMI 48 Investigators. Edoxaban versus warfarin in patients with atrial fibrillation. N Engl J Med. 2013 Nov 28;369(22):2093-104. doi: 10.1056/NEJMoa1310907. Epub 2013 Nov 19. PMID: 24251359.

26. Forslund T, Komen JJ, Andersen M, Wettermark B, von Euler M, Mantel-Teeuwisse AK, Braunschweig F, Hjemdahl P. Improved Stroke Prevention in Atrial Fibrillation After the Introduction of Non-Vitamin K Antagonist Oral Anticoagulants. Stroke. 2018 Sep;49(9):2122-2128. doi: 10.1161/STROKEAHA.118.021990. PMID: 30354995.

27. Ruff CT, Giugliano RP, Braunwald E, Hoffman EB, Deenadayalu N, Ezekowitz MD, Camm AJ, Weitz JI, Lewis BS, Parkhomenko A, Yamashita T, Antman EM. Comparison of the efficacy and safety of new oral anticoagulants with warfarin in patients with atrial fibrillation: a meta-analysis of randomised trials. Lancet. 2014 Mar 15;383(9921):955-62. doi: 10.1016/S0140-6736(13)62343-0. Epub 2013 Dec 4. PMID: 24315724.

28. Behdarvand B, Karanges EA, Bero L. Pharmaceutical industry funding of events for healthcare professionals on non-Vitamin K oral anticoagulants in Australia: An observational study. BMJ Open. 2019;9(8):1-11. doi:10.1136/bmjopen-2019-030253.

Page $8 / 13$ 
29. Suzuki S, Yamashita T, Okumura K, Atarashi H, Akao M, Ogawa H, Inoue H. Incidence of ischemic stroke in Japanese patients with atrial fibrillation not receiving anticoagulation therapy-pooled analysis of the Shinken Database, J-RHYTHM Registry, and Fushimi AF Registry. Circ J. 2015;79(2):432-8. doi: 10.1253/circj.CJ-14-1131. Epub 2014 Dec 11. PMID: 25501800.

30. Testa L, Trotta G, Abbate A, Agostoni P, Biondi-Zoccai GG. Low-dose aspirin for stroke prevention. Stroke. 2006 Jun;37(6):1356. doi: 10.1161/01.STR.0000222993.82870.50. Epub 2006 Apr 27. PMID: 16645127.

31. JCS Joint Working Group. Guidelines for elective percutaneous coronary intervention in patients with stable coronary artery disease (JCS 2011) published in 2012: Digest version. Circ J. 2013;77(6):1590-1607. doi:10.1253/circj.CJ-66-0065.

32. Yasuda S, Kaikita K, Akao M, Ako J, Matoba T, Nakamura M, Miyauchi K, Hagiwara N, Kimura K, Hirayama A, Matsui K, Ogawa H; AFIRE Investigators. Antithrombotic Therapy for Atrial Fibrillation with Stable Coronary Disease. N Engl J Med. 2019 Sep 19;381(12):1103-1113. doi: 10.1056/NEJMoa1904143. Epub 2019 Sep 2. PMID: 31475793.

33. Chang SH, Chou IJ, Yeh YH, Chiou MJ, Wen MS, Kuo CT, See LC, Kuo CF. Association Between Use of Non-Vitamin K Oral Anticoagulants With and Without Concurrent Medications and Risk of Major Bleeding in Nonvalvular Atrial Fibrillation. JAMA. 2017 Oct 3;318(13):12501259. doi: 10.1001/jama.2017.13883. PMID: 28973247; PMCID: PMC581885.

\section{Tables}

Table 1. Characteristics of atrial fibrillation (Af) patients aged $\geq 65$ years (2015)

\begin{tabular}{|c|c|c|c|c|c|c|c|c|}
\hline \multirow{3}{*}{$\begin{array}{l}\text { Variable } \\
\text { Age (years) Mean (SD) }\end{array}$} & \multirow{2}{*}{\multicolumn{2}{|c|}{$\begin{array}{l}\text { All } \\
\qquad n=12,076 \rrbracket\end{array}$}} & \multirow{2}{*}{\multicolumn{2}{|c|}{$\begin{array}{l}\text { VKA } \\
\text { 『n=2,991】 }\end{array}$}} & \multirow{2}{*}{\multicolumn{2}{|c|}{$\begin{array}{l}\text { DOAC } \\
\qquad n=3,770 \rrbracket\end{array}$}} & \multirow{2}{*}{\multicolumn{2}{|c|}{$\begin{array}{l}\text { None } \\
\bigotimes n=5,315 \rrbracket\end{array}$}} \\
\hline & & & & & & & & \\
\hline & 78.8 & $(7.7)$ & 79.1 & $(7.6)$ & 77.9 & (7.3) & 79.2 & $(8.1)$ \\
\hline Female n (\%) & 2,724 & $(41)$ & 1,184 & $(40)$ & 1559 & (41) & 2447 & $(46)$ \\
\hline $\mathrm{CHADS}_{2}$ score Mean (SD) & 2.5 & $(1.4)$ & 3.0 & $(1.3)$ & 2.7 & $(1.3)$ & 2.1 & $(1.3)$ \\
\hline $\mathrm{CHA}_{2} \mathrm{DS}_{2}$-VASc score Mean (SD) & 4.1 & $(1.5)$ & 4.5 & $(1.4)$ & 4.2 & $(1.5)$ & 3.7 & (1.5) \\
\hline HAS-BLED score Mean (SD) & 2.6 & $(1.1)$ & 2.9 & $(1.0)$ & 2.7 & $(1.0)$ & 2.3 & $(1.1)$ \\
\hline \multicolumn{9}{|l|}{ Comorbidities n (\%) } \\
\hline Cerebral infarction/TIA & 2,995 & $(25)$ & 832 & $(28)$ & 977 & $(26)$ & 1,164 & $(22)$ \\
\hline Heart failure & 6,411 & $(53)$ & 1,931 & $(65)$ & 1,997 & $(53)$ & 2,447 & $(46)$ \\
\hline Vascular disease & 1,609 & (13) & 431 & $(14)$ & 461 & (12) & 709 & (13) \\
\hline Chronic kidney disease & 1,342 & $(11)$ & 422 & $(14)$ & 292 & (8) & 622 & (12) \\
\hline Liver damage & 2,403 & $(20)$ & 599 & $(20)$ & 711 & (19) & 1,079 & $(20)$ \\
\hline Bleeding & 2727 & $(23)$ & 773 & $(26)$ & 760 & $(20)$ & 1,183 & $(22)$ \\
\hline Alcoholism & 147 & $(1.2)$ & 40 & $(1.3)$ & 47 & $(1.2)$ & 59 & $(1.1)$ \\
\hline Hypertension & 7,910 & $(65)$ & 2,583 & $(86)$ & 3,051 & (81) & 2,226 & $(42)$ \\
\hline Diabetes mellitus & 1,723 & $(14)$ & 545 & $(18)$ & 702 & (19) & 467 & (9) \\
\hline Dialysis & 142 & $(1.2)$ & 46 & $(1.5)$ & 1 & $(0.0)$ & 95 & $(1.8)$ \\
\hline \multicolumn{9}{|l|}{ Concomitant drugs $\mathrm{n}(\%)$} \\
\hline Antiplatelet drugs & 702 & $(5.8)$ & 174 & $(5.8)$ & 195 & $(5.2)$ & 327 & $(6.2)$ \\
\hline NSAIDs & 2,005 & $(17)$ & 584 & (18) & 679 & (18) & 762 & (14) \\
\hline
\end{tabular}

${ }^{*} \mathrm{CHADS}_{2}$ score: heart failure, hypertension, age $\geq 75$ years, diabetes mellitus, prior cerebral infarction, or TIA(doubled)

$+\mathrm{CHA}_{2} \mathrm{DS}_{2}$-VASc score: heart failure, hypertension, age $\geq 75 y$ ears(doubled), diabetes mellitus, prior cerebral infarction or TIA(doubled), vascular disease, age 65-74 years, female sex 
łHAS-BLED score: hypertension, renal and hepatic dysfunction, stroke, bleeding, age $\geq 65$ years, concomitant antiplatelet drugs and NSAIDs, alcoholism

§TIA: transient ischemic attack, ||NSAIDs: non-steroidal anti-inflammatory drugs

Table 2. The proportion of anticoagulant prescriptions by group of stratified cerebral infarction risk and bleeding risk

\begin{tabular}{|c|c|c|c|c|c|c|c|c|c|c|c|c|c|c|c|c|c|c|c|c|}
\hline \multirow{3}{*}{ Group } & \multicolumn{2}{|l|}{2011} & \multicolumn{4}{|c|}{2012} & \multicolumn{4}{|c|}{2013} & \multicolumn{4}{|c|}{2014} & \multicolumn{5}{|c|}{2015} & \multirow[b]{2}{*}{ Total } \\
\hline & \multicolumn{2}{|c|}{ Af DOAC } & VKA & Total & \multicolumn{2}{|c|}{ Af DOAC } & \multicolumn{2}{|r|}{ Total } & \multicolumn{2}{|c|}{ Af DOAC } & VKA & Total & \multicolumn{2}{|c|}{ Af DOAC } & VKA & Total & \multicolumn{2}{|c|}{ Af DOAC } & VKA & \\
\hline & $\mathrm{n}$ & n (\%) & n (\%) & n (\%) & $\mathrm{n}$ & n (\%) & n (\%) & $\mathrm{n}(\%)$ & $\mathrm{n}$ & n (\%) & n (\%) & n (\%) & $\mathrm{n}$ & n (\%) & n (\%) & n $(\%)$ & $\mathrm{n}$ & n (\%) & n (\%) & n (\%) \\
\hline 1 & 345 & $8(2.3)$ & $53(15)$ & ) 61 (18) & 369 & $18(4.9)$ & $57(15)$ & $75(20)$ & 398 & $46(12)$ & $55(14)$ & 101 & 386 & 68 (18) & $38(9.8)$ & 106 & 397 & $78(20)$ & 27 (6.8) & $105(26)$ \\
\hline 2 & 19 & $1(5.3)$ & $6(32)$ & 7 (37) & 20 & $1(5.0)$ & $3(15)$ & $4(20)$ & 33 & $2(6.1)$ & $9(27)$ & $11(33)$ & 26 & $3(12)$ & $3(12)$ & $6(23)$ & 38 & $6(16)$ & $3(7.9)$ & $9(24)$ \\
\hline Total $(1+2)$ & 364 & $9(2.5)$ & $59(16)$ & 68 (19) & 389 & $19(4.9)$ & $60(15)$ & $79(20)$ & 431 & $48(11)$ & $64(15)$ & $112(26)$ & 412 & 71 (17) & $41(10)$ & $112(27)$ & 434 & 84 (19) & $30(6.9)$ & $114(26)$ \\
\hline 3 & 4233 & $146(3.4)$ & $1254(30)$ & ) 1400 (33) 4 & 4768 & $307(6.4) 1$ & 1485 (31) 1 & $1792(38) 5$ & 5079 & 718 (14) & 1404 & $2122(42)$ & 5547 & 1279 & 1265 (23) & $2544(46)$ & 5897 & 1706 & 1169 (20) & $2875(49)$ \\
\hline 4 & 3587 & $184(5.1)$ & 1738 (49) & ) $1922(54) 4$ & 4058 & 337 (8.3)1 & $1882(46) 2$ & $2219(55) 4$ & 4610 & 798 (17) & 1898 & 2696 (59) & 5211 & 1340 (26) 1 & 1895 (36) & 3235 (62) & 5745 & 1980 & $1792(31)$ & $3772(66)$ \\
\hline Total $(3+4)$ & 7820 & $330(4.2)$ & 2992 (38) & 3322 (43)8 & 8826 & $644(7.3) 3$ & 3367 (38) 4 & $4011(45) 9$ & 9689 & $1516(16)$ & 3302 & $4818(50)$ & 10758 & 2619 & 3160 (29) & $5779(54) 1$ & 11642 & 3725 & 2991 (26) & $6716(58)$ \\
\hline
\end{tabular}

Group $1 \frac{\mathrm{CHA}_{2} \mathrm{DS}_{2}-\mathrm{VASc}=1}{\mathrm{HAS}-\mathrm{BLED}=1,2}$

HAS-BLED = 1,2
Group $2 \quad \mathrm{CHA}_{2} \mathrm{DS}_{2}-\mathrm{VASc}=1$
HAS-BLED $\geqq 3$

Group 3

$\mathrm{CHA}_{2} \mathrm{DS}_{2}-\mathrm{VASc} \geqq 2$

HAS-BLED = 1,2

Group $4 \frac{\mathrm{CHA}_{2} \mathrm{DS}_{2}-\mathrm{VASc} \geqq 2}{\mathrm{HAS}-\mathrm{BLED} \geqq 3}$

*Af: Atrial fibrillation

+VKA: Vitamin K antagonist

‡DOAC: direct oral anticoagulant

$\S \mathrm{CHA}_{2} \mathrm{DS}_{2}$-VASc score: heart failure, hypertension, age $\geq 75 y$ ears(doubled), diabetes mellitus, prior cerebral infarction or TIA(doubled), vascular disease, age 65-74 years, female sex

॥HAS-BLED score: hypertension, renal and hepatic dysfunction, stroke, bleeding, age $\geq 65$ years, concomitant antiplatelet drugs an NSAIDs, alcoholism

\#NSAIDs: non-steroidal anti-inflammatory drugs; **TIA: transient ischemic attack. 
Figures

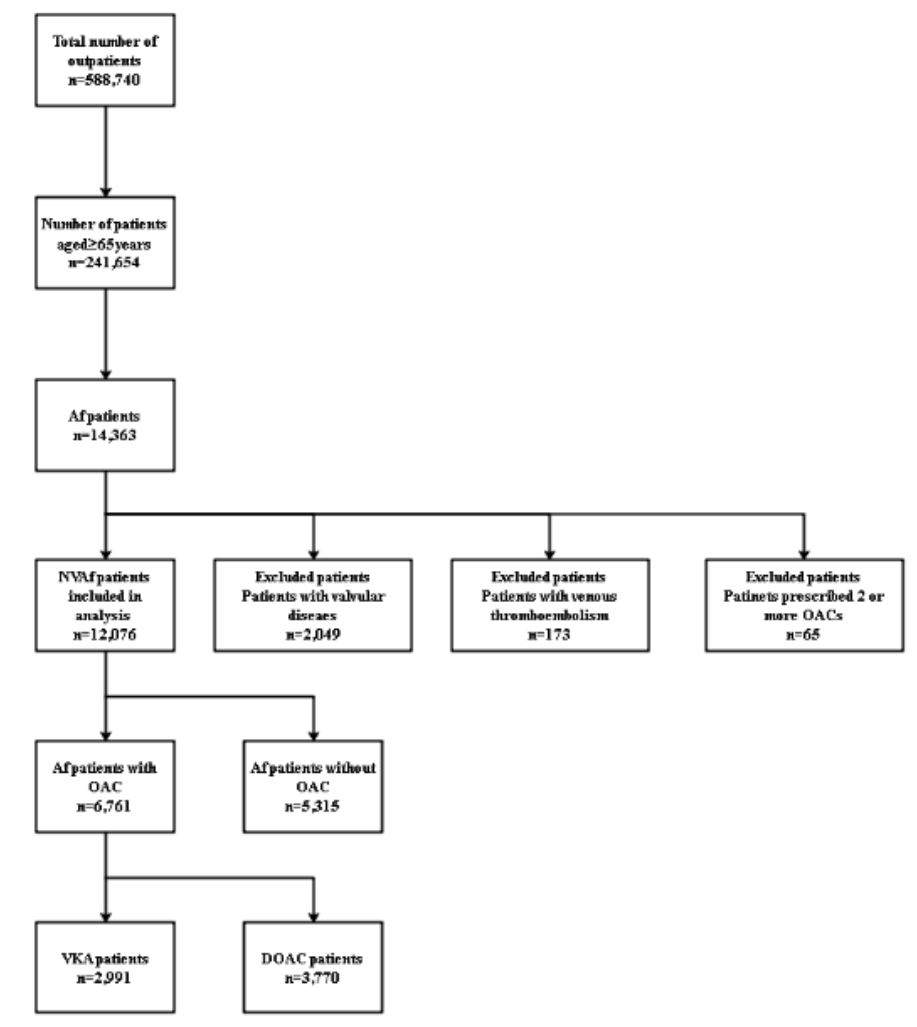

Figure 1. Flowchart of subject extraction (2015)

Figure 1

Flowchart of subject extraction (2015) 


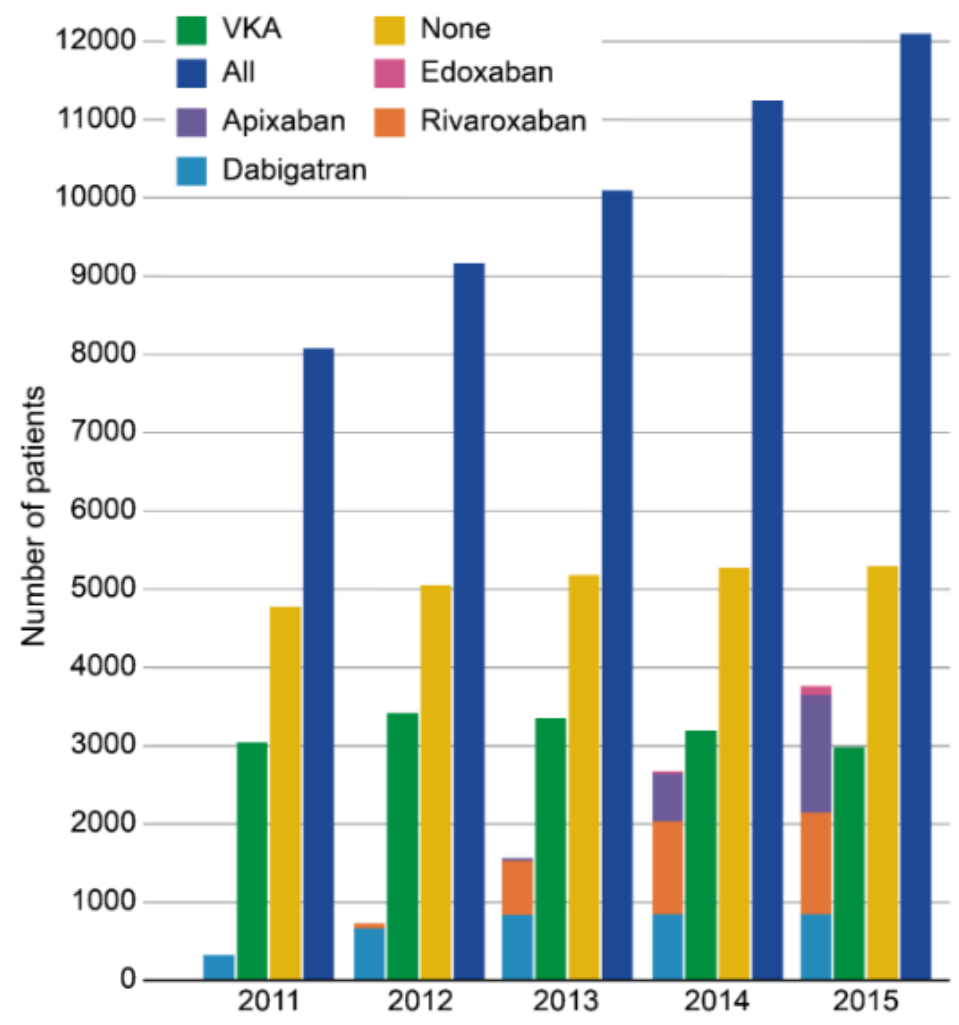

Figure 2. Changes over time in anticoagulant prescriptions

\section{Figure 2}

Changes over time in anticoagulant prescriptions 


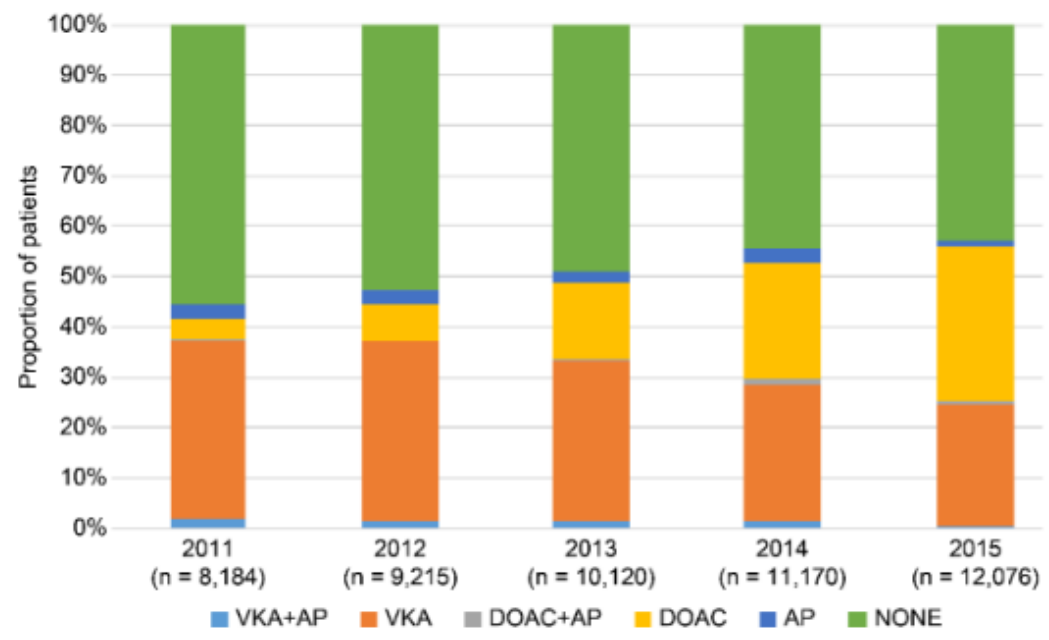

Figure 3. Proportions of prescriptions for anticoagulants and AP among all Af patients

\section{Figure 3}

Proportions of prescriptions for anticoagulants and AP among all Af patients

\section{Supplementary Files}

This is a list of supplementary files associated with this preprint. Click to download.

- N.TsujiS1table.pdf 